\title{
A BAGAGEM DO PIBID PARA A FORMAÇÃO INICIAL DOCENTE E PARA A CONSTRUÇÃO DA IDENTIDADE PROFISSIONAL
}

\author{
PIBID EXPERIENCES FOR PRE-SERVICE LANGUAGE \\ TEACHER EDUCATION AND FOR CONSTRUCTION OF \\ PROFESSIONAL IDENTITY
}

\section{Hélvio Frank Oliveira*}

\section{RESUMO}

A partir de uma experiência situada em uma universidade pública do interior do Estado de Goiás, durante os dois anos de implantação do Programa Institucional de Bolsas de Iniciação à Docência (PIBID) na área de Letras/português, o objetivo deste artigo é investigar e discutir as bagagens ${ }^{1}$ deixadas pelo referido programa a licenciandos no que tange à sua formação inicial docente e à construção de suas identidades profissionais. Para isso, um estudo de caso de orientação qualitativo-interpretativista foi desenvolvido com o referido grupo de estudantes bolsistas. As bases para a interpretação deste trabalho foram o olhar narrativo do pesquisador, na condição de observador-participante e de coordenador do subprojeto, e ainda os seguintes instrumentos de pesquisa colhidos dos participantes: histórias de vida, entrevista semiestruturada e sessões de reflexão colaborativa promovidas no decorrer de alguns encontros semanais do grupo. Os resultados indicam a potencial relevância do projeto para o fortalecimento da identidade profissional docente - tanto em relação à prática quanto à pesquisa em sala de aula -, ao mesmo tempo que se vislumbra a evidente necessidade de acompanhamento de outras políticas e demais atividades pedagógicas voltadas às licenciaturas no que se refere ao empoderamento do futuro professor para a continuação da carreira após o término da graduação.

Palavras-chave: PIBID; Experiências; Identidade docente.

\section{ABSTRACT}

From a project at a public university in State of Goiás, during two years of implementation of PIBID, Institutional Scholarship Program Introduction to Teaching, in the area of Language Teaching, this paper claims to investigate and discuss the experiences developed by this educational program to undergraduate students with regard to their initial teacher training and the construction of their professional identities. For this, a case study of qualitativeinterpretative was conducted with a group of pre-service teachers. Researcher's view on narratives inquire, as an observer-participant and subproject coordinator, is base for

\footnotetext{
* Universidade Estadual de Goiás (UFG), Anápolis, GO, Brasil. helviofrank@hotmail.com

1. Neste texto, farei alusão à metáfora "bagagem" em referência aos conhecimentos empíricos construídos pelos bolsistas do Programa Institucional de Bolsas de Iniciação à Docência (PIBID) ao longo da experiência vivida.
} 
interpreting this work, and also the following research tools collected from the participants: life stories, semi-structured interview and reflection and collaboration sessions promoted during some weekly group meetings. Results indicate the potential relevance of the project for strengthening the teaching professional identity - both in terms of practice and research in the classroom - at the same time it shows obvious need for monitoring of other policies and other educational activities aimed at undergraduate with regard to the empowerment of the future teacher for continued career after the graduation.

Palavras-chave: PIBID; Experiences; Teacher's identity.

\section{INTRODUÇÃO}

Diversos estudos na área de Linguística Aplicada têm sinalizado a relevância do PIBID para a formação inicial docente (MATEUS et al., 2013), para a educação de alunos da escola pública (ANDRADE et al., 2015; GUEDES et al., 2015; entre outros $^{2}$ ) e para a formação continuada de professores (MAFRA; CORRÊA, 2015; PASSONI et al., 2013; SILVA; GOMES, 2013). São abundantes as contribuições do Programa Institucional de Bolsas de Iniciação à Docência (doravante PIBID) direcionadas ao contexto de licenciatura no que tange à aproximação entre teoria e prática (JORDÃO et al., 2013; TEIXEIRA; VASCONCELOS, 2015) e entre universidade e escola (EL KADRI et al., 2013); à oportunidade de reflexão sobre ações e mudança no ensino-aprendizagem escolar (ROZENFELD; SALOMÃO, 2014; SILVA; GOMES, 2013; NEITZEL et al., 2013); e ao processo de colaboração, leitura e ressignificação da identidade e do trabalho docente por parte dos envolvidos (AUDI et al., 2013; BERGAMASCHI, ALMEIDA, 2013; PASSONI et al., 2013; RORRATO, 2014).

Embora inegáveis os benefícios, conforme salientam Mateus et al. (2015, p. 47) ancorados em Fairclough (2010), é necessário refletir sobre a lógica hegemônica que a tecnologização dos discursos, via naturalização de práticas e relações de poder, confere ao programa institucional, no momento em que lhe outorga a condição de agente messiânico de práticas e o lança como única alternativa para a formação inicial docente. Longe de tomá-lo como "entidade salvadora", este texto leva em coro a crítica exposta ao mesmo tempo em que reitera a necessidade de continuar mapeando as experiências, positivas e negativas, ocasionadas com o PIBID. Como afirmam Mateus et al. (2013), por meio da concessão de bolsas, o projeto potencializa e gera visibilidade social para as práticas institucionais pedagógicas, bem como possibilita a projeção de novos papéis sociais à licenciatura e à profissão docente.

2. Em 2015, foram lançados dois volumes da revista "Ao pé da letra" - Revista de Graduação da Universidade Federal de Pernambuco - dedicados especialmente ao PIBID Letras. 
Se a força potencial qualitativa do PIBID se reserva na relevância em propor, de modo ativo, novos modos de articular a práxis educacional, como vários trabalhos destacaram, esse fazer dentro da licenciatura parece servir hoje, no contexto em que vivemos, como processo por meio do qual sujeitos testam e legitimam suas possibilidades de mudança. Logo, o que se torna fulcral é a crítica contextualizada a partir da implementação de uma ação situada, tal qual a proposta aqui apresentada.

Neste artigo, reflito sobre uma investigação contextualizada do PIBID cujo propósito se deu no rastreamento e na discussão sobre as bagagens - positivas e/ou negativas - deixadas pelo programa aos licenciandos, concernentes a sua formação inicial docente e à construção de suas identidades profissionais. Para isso, será empregada a metáfora da bagagem referente a um conjunto de itens pessoais que servem de auxílio a viajantes, e levadas em consideração as reflexões de VieiraAbrahão (2012), para quem a bagagem é um elemento muito comum e, ao mesmo tempo, relevante na formação inicial docente. A bagagem é uma espécie de recurso que o viajante ativamente conduz ou não consigo durante a viagem. Quem se locomove, portanto, é o sujeito que, na condição de viajante ao desconhecido mundo da licenciatura e da docência, já traz consigo bagagens (experiências) pessoais. Ao se deparar com novas experiências no decorrer do caminho (curso), decide quais dos itens carregará consigo de modo a constituir sua identidade profissional (OLIVEIRA, 2013).

\section{PIBID, FORMAÇÃO DOCENTE E CONSTRUÇÃO DA IDENTIDADE PROFISSIONAL}

Surgido inicialmente no ano de 2007, na tentativa de reduzir a precariedade da formação docente em áreas com mais dificuldades de se encontrar professores, o PIBID, no que diz respeito à área de Letras, teve início apenas em $2010 \mathrm{com}$ a chamada pública do MEC/CAPES/FNDE sob o propósito de alavancar as licenciaturas (MATEUS et al., 2013). Na condição de programa governamental, o PIBID visa a inserir os graduandos no cotidiano das escolas públicas e, com isso, antecipar seu vínculo com a realidade escolar, seu futuro campo de atuação. Nesse contexto, constitui-se como possibilidade de criação de espaços em que a universidade e a escola de educação básica, ao aproximar teoria e prática, engajamse na formação dos licenciandos.

Sob uma vertente crítica, para El Kadri et al. (2013, p. 105-106), o PIBID consiste numa "prática social" implementada por políticas governamentais educacionais recentes que permitem, no campo da formação docente, reconceitualizar e recontextualizar práticas produzidas na relação escola- 
universidade, de modo a potencialmente romper com posicionamentos sociais que "operam para a submissão". Essa condição daria o contorno sinalizado por Audi et al. (2013, p. 98), para quem o elo universidade-escola construído a partir do PIBID possibilita a produção de práticas pedagógicas voltadas à construção de conhecimento localmente significativa aos alunos.

Compreendo que o PIBID, assim como outras etapas de formação docente, por se consolidar em atividades institucionais, sociais e relacionais entre indivíduos munidos de um mesmo propósito, constitui-se de conhecimentos potencialmente significativos em relação à docência. Na esteira dessa socialização, para incluir Dubar (1997), as identidades se movimentam. Por essa razão, ao desenvolverem suas práticas e realidades acerca da docência, da licenciatura e do trabalho profissional, os participantes do PIBID automaticamente se definem como indivíduos sociais e constroem suas identidades, na medida em que interagem com professores e colegas e com as próprias experiências educacionais. Para Mateus (2011), as experiências e a vivência com o/s outro/s mediadas pela linguagem/interação são importantes elementos para a construção das identidades docentes.

Piconi e Mateus (2011), por intermédio do PIBID, averiguaram que as participantes de seu estudo, sujeitas à alteridade inerente aos encontros educativos comuns ao programa, ressignificaram e refizeram suas identidades docentes. Passoni et al. (2013), por sua vez, entendem que a identidade, assim como a aprendizagem, no que se refere à formação de professores, consiste em conceitos intrínsecos, indissociáveis, subjacentes ao processo de formação docente. Dessa forma, diversos fatores - históricos, sociológicos, psicológicos, cognitivos e culturais - tornam-se grandes influenciadores de sua constituição e conceituação.

Para Silva (2009, p.17), esses condicionantes se unem à construção da identidade por intermédio das práticas de significação e dos sistemas simbólicos por meio dos quais os significados são produzidos e representados. Como avalia o autor, "[é] por meio dos significados produzidos pelas representações que damos sentido à nossa experiência e àquilo que somos. Podemos inclusive sugerir que esses sistemas simbólicos tornam possível aquilo que somos e aquilo no qual podemos nos tornar".

A identidade profissional docente, segundo Marcelo (2009), equivale a construções que permeiam a vida profissional e passam pela formação inicial e pelos diferentes espaços institucionais em que a profissão é desenvolvida numa dimensão espacial e temporal. Tem como orientação os saberes profissionais e as atribuições que integram a instância profissional, caracterizados a partir das experiências, das 
práticas sociais, das representações e das tomadas de decisões nesse meio. Pimenta (2012, p. 19) acrescenta que

[a] identidade profissional se constrói, pois, a partir de significações sociais; da revisão constante dos significados sociais da profissão; da revisão das tradições. Mas também na reafirmação de práticas consagradas culturalmente e que permanecem significativas. [...] Constrói-se, também, pelo significado que cada professor, enquanto ator e autor confere à atividade docente no seu cotidiano a partir de seus valores, de seu modo de situar-se no mundo, de suas angústias e anseios, do sentido que tem em sua vida de professor.

Por analogia, o PIBID contém significados que o fazem entremear-se aos espaços sociais em que, ecoando Nóvoa (1992), permeiam-se três dimensões fundamentais à identidade: o desenvolvimento pessoal, estruturado nos processos individuais de construção do professor; o desenvolvimento profissional, responsável pelos aspectos da profissionalização do professor; e, por fim, o desenvolvimento institucional, demarcado pelos objetivos educacionais e investimentos da instituição nos planos social e político.

\section{O PIBID DE LETRAS (PORTUGUÊS) NO CONTEXTO DE INVESTIGAÇÃO}

No contexto de investigação, o subprojeto ao qual os participantes desta pesquisa pertenciam iniciou-se em janeiro de 2014 e tinha como pressuposto teórico a perspectiva dos letramentos sociais (STREET, 2014) e dos multiletramentos (ROJO, 2013) na área de língua portuguesa. A ideia era justamente trazer à tona letramentos que não estão inscritos na esfera escolar, mas que igualmente compõem a vida social. Foram levadas em consideração, conforme critérios adotados para a seleção de bolsistas em edital para o determinado fim, as notas e a visão docente reflexiva e crítica do licenciando. A partir desses requisitos, foram classificados seis acadêmicos de Letras, os quais possuíam afinidade com as disciplinas de língua portuguesa e literatura. Fizeram parte do grupo de seis graduandos bolsistas, a supervisora da escola e o formador de professores.

Com relação à disciplina de língua portuguesa, os objetivos giravam em torno da desmistificação da ideia de letramento para além de uma proposta pautada no modelo autônomo, de modo a conscientizar professores e alunos em relação à característica ideológica do letramento em meio às diversas práticas sociais envolvendo o uso da língua/linguagem (BRASIL, 2006; GOIÁS, 2013). Para tanto, compreendiam as ações dos futuros professores envolvidos o diagnóstico, a discussão colaborativa à luz de teorias, o planejamento e elaboração de materiais e 
aulas, bem como a ação interventiva situada em turmas de primeiro e segundo anos do ensino médio de uma escola pública.

As atividades do PIBID eram desenvolvidas tanto nos espaços escolares quanto na universidade e estavam pautadas nos princípios de colaboração que subjazem teoricamente à perspectiva sociocultural de Vygotsky (1998) e à supervisão crítico-pedagógica de Smyth (1991). Na escola, em turmas de ensino médio, primeiramente os bolsistas observavam e vivenciavam as lacunas existentes no ensino-aprendizagem de língua portuguesa, por intermédio da etapa de diagnóstico. Depois, na escola, com o auxílio da supervisora, e na universidade, com o auxílio do formador, essas lacunas eram revisitadas e discutidas durante encontros pedagógicos. Geralmente, nessas reuniões semanais realizadas com formador, a supervisora da escola e os bolsistas, abriam-se espaços colaborativos e dialógicos, mediados pelas reflexões sobre problemáticas detectadas, em conjunto com as teorias lidas e discutidas, para uma futura ação em campo (SMYTH, 1991). De acordo com Passoni et al. (2013), as reuniões semanais, comuns aos grupos de PIBID, com foco nas sessões de diálogo coparticipativo, funcionam como espaços para a construção de conhecimentos localmente situados, os quais emergem da práxis colaborativa da proposta e como ações relevantes para o fortalecimento da identidade dos futuros professores engajados.

Por sua vez, os saberes disciplinares de língua portuguesa estavam alinhados ao ideal de formação docente vislumbrado pelo projeto. Na proposta desenvolvida, durante as discussões em grupo era dado um lugar de destaque à linguagem como produtora de realidade (PENNYCOOK, 2001) e de construção de identidades (MOITA LOPES, 2002) na formação e emancipação de todos os integrantes. Além da reflexão crítica sobre o ensino-aprendizagem da língua portuguesa, procurávamos construir uma formação docente crítica e voltada aos problemas sociais.

Essa condição de atuação crítica por intermédio do PIBID, para Jordão (2013), possibilita ressignificações acerca da língua-disciplina do projeto e acerca da própria formação docente à medida que os pares colaboram uns com os outros. Acrescentando El Kadri et al. (2013, p. 125), o ganho do PIBID está na colaboração produzida pelos envolvidos, a qual proporciona espaços de reconhecimento e de valorização mútuos e, além disso, possui grande impacto no sentido de intervir diretamente na configuração de diferentes relações entre universidade e escola. De acordo com as autoras, "os discursos que produzimos nos encontros com o/s outro/s são, ao mesmo tempo, possibilitados e constrangidos pelas estruturas e práticas sociais, e potencializadores e inibidores das possibilidades de agir". 


\section{METODOLOGIA}

Os dados discutidos informados por este artigo são provenientes de um estudo de caso qualitativo-interpretativista realizado com apenas cinco dos licenciandos bolsistas do curso de Letras (português/inglês) no ano de 2015, em virtude de um dos pibidianos ter deixado o projeto antes da conclusão dos vinte e quatro meses. Quatro participantes se declararam pertencentes ao sexo feminino e um participante ao sexo masculino, todos eles perfaziam média de idade entre 19 e 30 anos.

Formam as bases para a interpretação desta pesquisa o olhar narrativo do pesquisador, na condição de observador-participante e de coordenador do subprojeto, e ainda os seguintes instrumentos de pesquisa gerados com os participantes: histórias de vida, entrevista semiestruturada e sessões de reflexão colaborativa promovidas no decorrer de alguns encontros semanais do grupo.

A análise triangular produzida levou em consideração o agrupamento das categorias de temas e conteúdos de maior recorrência, ateve-se aos locais de produção narrativo-discursiva, sem o impedimento da compreensão de sentido global situado de suas construções. Está, por fim, alinhada ao propósito especialmente delineado neste artigo. Por questões éticas, pseudônimos foram escolhidos pelos próprios participantes e os excertos que ilustram a discussão são tratados como "narrativas" (OLIVEIRA, 2013), uma vez adaptados à variedade formal de escrita da língua com a manutenção do léxico utilizado pelo participante.

\section{UMA INTERPRETAÇÃO DOS DADOS}

Sem conhecimento aprofundado sobre o que seria o PIBID, a experiência inédita no contexto de investigação, que também ecoou outros estudos (AUDI et al., 2013), inicia-se motivada pela construção de conhecimentos acadêmicos e também pela oportunidade de recebimento de bolsa.

[1] [Entrei no PIBID para] poder potencializar minha formação, né. Apesar da minha formação ser boa, ter bons professores, boas leituras, eu acho que é um bônus a mais, né, de leitura, de bagagem teórica. [...] Construir alguma coisa, né. Acarretar mais alguma coisa à minha formação. (Carlos)

[2] No início do segundo ano, eu já estava tentando ganhar uma bolsa na faculdade. Não deu certo. Quando ingressei no terceiro ano, saiu essa bolsa do PIBID. A priori, era com relação à bolsa mesmo, ao dinheiro. Inclusive, tinha pouco conhecimento do que vinha a ser o PIBID. (Drica) 
A predisposição ao PIBID, seja ela construída a partir de necessidade financeira ou de aprendizagem, assim como qualquer outra atividade formativa de licenciatura, pode se tornar condição plena para a construção da identidade docente e de muitas ressignificações em torno da profissão (PIMENTA, 2012) ao proporcionar o contato direto com a sala de aula, especialmente, como consideram Audi et al. (2013), aquelas cristalizadas por visões tradicionais da formação de professores sob um modelo cartesiano. Esse princípio é justamente o ponto de partida para iniciarmos a viagem.

\section{As bagagens do PIBID}

Ainda que concentremos, a seguir, experiências positivas em relação ao PIBID desenvolvido em turmas de ensino médio da escola pública, a exemplo do que ocorreu no contexto de pesquisa de Oliveira et al. (2015), os participantes não ignoram a problemática existente na educação básica, tampouco são ingênuos quanto às forças sociais e institucionais presentes na relação entre universidade e escola, na tentativa de influenciar o modo de pensar e de agir. Aliás, a meu ver são exatamente tais condições de vivência ao longo da formação inicial de professores (como os estágios, entre outras experiências formativas) que, dada sua complexidade de abrangência relacionada ao trabalho docente, colaboram e influenciam na construção da identidade profissional. A partir disso, foram listadas 5 constatações mencionadas pelos participantes ao longo de suas reflexões narrativas, as quais serão discutidas a seguir:

\section{1) Ressignificação de crenças da profissão e/ou do trabalho docente}

O PIBID trouxe possibilidades de ressignificação das próprias crenças dos integrantes acerca do trabalho docente e/ou da profissão. Os participantes dizem, muitas vezes, ressignificar suas próprias crenças à medida que desenvolvem e participam do projeto:

[3] Acredito que o PIBID seja uma oportunidade também de refletir sobre os problemas que se encontram dentro da sala de aula, na docência. Problemas relativos a essas próprias imagens que a gente cria sobre ser professor ou não. [...] Às vezes a gente entra num curso de licenciatura com aquele discurso que ser professora seria a última das opções, aquela coisa complicada e tal. Realmente tem seus obstáculos, mas a gratificação da profissão supera isso. Essa gratificação percebi mediante os trabalhos que a gente desenvolveu no PIBID. (Gonçalves) 
Não se trata de uma proposta que maquia o modus operandi da docência no cenário histórico e atual. Como vimos, os participantes estão céticos e conscientes da realidade profissional situada. No entanto, envolver-se no PIBID, a exemplo do que ocorreu com os participantes de Jordão (2013), significou-lhes a atribuição de novos sentidos à escola pública, bem como a descoberta de outros caminhos possíveis de ação do magistério diante da constatação de problemas existentes em sala de aula. Aliás, como reflete Lima et al. (2015, p. 56), "a vivência de professores como autores de suas próprias atividades para a sala de aula, por vezes, não é contemplada nas grades curriculares de cursos de licenciatura", e isso é um ponto positivo verificado nessa proposta de PIBID.

Talvez guiados pelas discussões teóricas, cultura da confiança e desejo de mudança coletiva e colaborativamente produzidos, como consta das programações do projeto, esses integrantes, ao invés de reforçarem a imagem decadente do professor, optam, por meio da ação, por ressignificarem o status quo da docência. Uma característica essencial sobre esse fato é os integrantes do PIBID - formador de professores, professores supervisores e alunos - sentirem-se pares, cúmplices, unimúltiplos (AUDI et al., 2013; MATEUS, 2011).

Para Gomes et al. (2015, p. 86), é inegável a condição que a "docência compartilhada" provoca nos pibidianos ao lhes oportunizarem momentos de crescimento mútuo. Nesse caso, os conhecimentos prévios, adquiridos, são compartilhados, ideias são expostas e o sentido da aprendizagem, da escola e da educação é (re)construído. Além disso, no desenvolvimento do PIBID, o encontro com o/s outro/s possibilita outras mediações. Para Mateus (2011, p. 190), "é na experiência com o outro que (re)criamos nossas identidades, aquilo que somos e que desejamos ser".

Colocar-se na condição do outro, no caso, do professor, ao observar as realidades por ele vivenciadas no ambiente escolar, para a pibidiana Flor do Campo significou entender a condição docente de modo contextualizado. O sentir-se na pele quando se tem a bagagem apenas de uma outra visão institucional é comum aos alunos que participam do PIBID, e essa condição pode corroborar o potencial de reflexão sobre o estar e o vir a ser. Consequentemente, em algum sentido a identidade docente é fortalecida, porque o diálogo com outros espaços institucionais permite a reflexão de outros espaços, a princípio, ainda invisíveis até a chegada do outro (JORDÃO, 2013).

[4] Nós vimos, no caso da professora [supervisora da escola], ela trabalhava com a aula contextualizada. Então, você via como a reação dos alunos e, às vezes, você está de fora, e você tem uma visão diferente, né, do professor que está ali. E isso nos ajudou, me ajudou a pensar mais no meu papel enquanto professora, quando eu estiver atuando, né. (Flor do Campo) 
Convém destacar que faz parte de alguns subprojetos o diálogo do pibidiano com o profissional supervisor acerca da ação observada/praticada. Entendemos, nesse caso, a essencial tarefa que possuem as sessões compartilhadas no sentido de influenciar as mudanças nas práticas pedagógicas vigentes. Sem dúvida, o olhar e a reflexão provocados pelo/s outro/s, segundo Smith (1991), podem exercer sobre nós outros sentidos. Para a condição docente, se balizada com teorias e leituras que fundamentam o "por que se faz como se faz", essa estratégia de colaboração e (com) partilha, além de se caracterizar como uma etapa fundamental à formação docente, tendo em vista que incentiva o desenvolvimento da prática reflexiva (GOMES et al., 2015), a meu ver, pode incorrer em diversos níveis de empoderamento docente.

\section{2) Promoção da autonomia}

A noção de ressignificação parece seguir reforçando - ou mesmo reforçada por - autonomia profissional. Na condição de futuros professores, a vontade de agir, intervir e de mudar a realidade observada e diagnosticada parece impulsionar as reflexões que se produzem, denotando a identificação que os participantes possuem com a profissão. Para Silva e Gomes (2013), seria exatamente este o objetivo do PIBID: (trans)formar professores de línguas de modo a construir cidadãos protagonistas, reflexivos e emancipados.

[5] Pelo fato de [no PIBID] haver um tempo de observação, de elaborar toda uma intervenção e tal, você parece que começa a perceber como que os professores têm que refletir mais sobre a realidade da sala de aula, começa a perceber melhor questões de como você pode intervir para melhorar. (Gonçalves)

[6] Porque se consolida geralmente numa ação prática, o PIBID auxilia a gente a pensar noutras visões que temos de professor. O professor não é só aquele que está na sala de aula e ministra um conteúdo feito por outros. Por exemplo, ele deve ser um professor pesquisador! Então, o PIBID auxilia nisso. O professor tem que estar sempre refletindo sobre a sua prática. [...] Pesquisando, colocando as teorias, refletindo e colocando-as em prática nas suas aulas. Porque não adianta eu estudar que a gramática tem que ser contextualizada e eu não fazer isso nas minhas aulas, né? (Flor do Campo).

Como podemos inferir, se o PIBID aposta em atividades de observação, de diagnóstico e de intervenção escolar, certamente possibilita, como detectou o estudo de Mafra e Corrêa (2015), o desenvolvimento de várias capacidades docentes, entre elas, a de transposição didática, isto é, a capacidade de transformar o conhecimento científico em um conhecimento ensinável. Com efeito, a vivência em sala de aula, o envolvimento, a integração, seguidas de um plano de ação, contendo reflexão e investigação crítica sobre a própria prática do exercício, transformam a realidade. 
No caso das ações pibidianas desenvolvidas, caraterizadas pela lógica da pesquisaação, é comum que os alunos passem a construir em si, quase que naturalmente, a possibilidade de agir e mudar perante os desafios e as lacunas identificadas.

\section{3) Aproximação da teoria com a prática}

O contato e a vivência com o/s outro/s, com o trabalho docente, com a profissão, com a cultura escolar e de sala de aula, com os alunos, com as relações sociais dinâmicas ali presentes, com o diálogo com os pares, concomitante à pesquisa e reflexão teórica, coopera para uma cultura de confiança construída com base no mesmo ideal profissional e, ao mesmo tempo, promove o estreitamento entre agentes da escola e universidade, aproximando aspectos de ordem teórica e prática na formação inicial de professores. A exemplo do que ocorreu no estudo de Audi et al. (2013), dentre as possibilidades de alteração das estruturas vigentes na universidade por parte do PIBID, as ações desenvolvidas oportunizaram aos participantes romper com velhos paradigmas da formação docente e com a visão de ensino dicotomizada entre teoria e prática.

[7] Mudou muita coisa [em mim] esse tempo todo na graduação. Todas essas discussões em campo, as discussões com os colegas. Eu acho que a gente se forma não só como professor, mas a gente se forma como pessoa também. [...] Porque eu vi muitos lados que a teoria na faculdade não me mostra, né. Eu vi como que o aluno chega à sala. Às vezes, quais são os problemas que ele traz para a sala. Não só problemas em relação à disciplina de língua portuguesa, mas, sim, problemas familiares. Então, eu tive esse contato direto com os alunos, e isso de certo modo me cativou. Eu percebi que, além de professor, eu posso ser amigo deles e tal. E de certo modo, isso me chamou a atenção na profissão. E eu acho assim, que eu posso continuar a carreira, e eu quero. (Carlos)

Como salientam Cordeiro et al. (2015), a formação alternativa conduzida pelo PIBID alimenta o conhecimento teórico e prático, contanto que haja um trabalho cíclico de aperfeiçoamento de metodologias de ensino, de reflexão sobre as tarefas realizadas, de leitura, discussão e reflexão teórica sobre aspectos detectados, em correlação com a prática pedagógica. Todavia, convém destacar que, para que se consolidem alguns desses aspectos mencionados anteriormente, é crucial a existência de um subprojeto de PIBID coerente e bem articulado, integrando teoria e prática. Acima de tudo, é preciso que incentive os licenciandos à docência e às transformações necessárias. Ou seja, um projeto que dê liberdade de ação e de problematização para os participantes construírem a si mesmos como docentes e fortalecerem sua identidade profissional. Nesse sentido, torna-se salutar observar a contextualização da ação interventiva que cada subprojeto produzirá nas realidades educacionais com as quais lida. Na interpretação de Silva e Gomes (2013) e de Audi 
et al. (2013), um objetivo de destaque do PIBID seria (trans)formar professores de línguas, de forma a integrar o ensino superior à educação básica. A esse respeito, Flor do Campo relata:

[8] O PIBID, tendo teoria e prática, pesquisa e ensino, né, isso é um ponto positivo, agora o PIBID que não tiver isso e não tiver a essência mesmo do programa, e ficar só no básico, sem teoria... O Arroyo falou algumas coisas interessantes sobre isso na palestra [que assisti ontem]: nem todos os subprojetos [do PIBID no Brasil] têm esse compromisso. (Flor do Campo)

Para a aproximação entre teoria e prática, Pereira et al. (2002, p. 194) sugerem a "metodologia da problematização", em que o profissional, engajado na reflexão e na investigação de sua prática, analisa os desafios a ele apresentados e pensa alternativas de solução. Esse tipo de ação questionadora pode preparar futuros professores para a mobilização do seu potencial social, político e ético, bem como oportunizar a tomada de consciência do mundo em que irá atuar para que se efetive uma mudança. Se adquirida e tornada rotina desde a formação inicial, a problematização, como os autores garantem, pode "se tornar parte da identidade profissional do professor" (PEREIRA et al. 2002, p. 200). Parece ter sido a associação de tais aspectos que aumentou em Anne a certeza de seguir com a profissão:

[9] Eu acho que o PIBID acrescentou: conhecimento científico, leitura, prática, aumentou ainda mais a minha certeza [de ser professora]. (Anne)

É inegável o acréscimo de conhecimentos especialmente teóricos advindos das diversas leituras realizadas sobre o trabalho docente e sobre a profissão para aqueles que participam do PIBID como suporte à ação de licenciar-se. Os conhecimentos e teorizações alcançadas, geralmente a envolver aspectos didáticopedagógicos, servem para a desmistificação do senso comum de que a atitude de ensinar se faz de modo intuitivo, sem a devida reflexão. Ou ainda para desconstruir ideias propagadas pela mídia, tais como "ser professor é uma missão", "ser professor é um dom", entre outras.

\section{4) Definição e consolidação da carreira profissional e de área de conhecimento}

Como observamos, o PIBID atua como suporte na definição e consolidação da profissão diante das incertezas profissionais do licenciando.

[10] [Entrei no PIBID] Pelo fato de acreditar que acrescentaria na minha carreira acadêmica, acrescentaria também no meu currículo, nas experiências. E também como uma forma de ter essa certeza se eu iria ser ou não professora. Porque, até então, eu tinha vontade. Só que parece que, às vezes, vinha certa dúvida. [...] Lá pelo segundo ano de graduação, terceiro 
ano, eu ficava meio em dúvida se eu queria ou não ser professora. Aí, depois dos trabalhos que eu desenvolvi no PIBID, questão de ir mesmo para a sala de aula, questão de desenvolver pesquisas relacionadas. Daí tive a certeza mesmo. (Gonçalves)

No relato de Gonçalves, podemos inferir que o PIBID consiste numa qualidade de prática social que se realiza também por intermédio do engajamento da própria participante. Por ora, não é o PIBID uma espécie de entidade que realiza os processos evidenciados, como ocorrera em Mateus et al. (2015). Além do mais, sem ignorar a condição de que determinadas perguntas metodológicas roteirizadas em instrumentos de pesquisa, dependendo da forma com que são feitas, podem enunciativamente conduzir a certos tipos de respostas, o PIBID, em sua condição de execução durante a licenciatura, no contexto de investigação apresentou, em maior repercussão, bagagens positivas aos participantes. O trabalho consolidado, no entanto, só pôde ser concretizado devido ao trabalho conjunto entre formador e professora em formação, no sentido de construírem nessa aluna caminhos para uma autonomia profissional. Além disso, os participantes indicaram o ingresso ao PIBID logo no primeiro ano da licenciatura, para que os licenciandos testassem a sua identidade docente. Nesse caso, pontuaram que o PIBID deveria envolver maior número de licenciandos:

[11] No primeiro ano tem que ter o PIBID. Eu estava até comentando com muitos colegas e professores, agora, colegas de profissão. Porque elas não conhecem o PIBID. Eu acho que ele motiva e oferece outros caminhos, mostra muitas coisas para o aluno quando chega ao primeiro ano [da licenciatura], por exemplo, e que não sabe se é isso [a docência] que vai querer. $\mathrm{E}$ com o estágio, depois, assusta e às vezes quer desistir. Porque, às vezes, tem experiências só negativas ou é pouco o tempo. (Flor do Campo)

[12] Eu acho que a sala inteira poderia participar de um projeto como esse. [...] Eu o indicaria a muitas pessoas. [...] Deveria estendê-lo a mais pessoas, né, a alunos do primeiro ano. Para que eles já tenham contato desde o início da faculdade. [...] Já seria um modo de incentivo à docência. Porque muitas pessoas caem literalmente na faculdade, por acaso, né. (Carlos)

Sem evitar a tecnologização dos discursos (FAIRCLOUGH, 2010 apud MATEUS et al., 2015), isto é, do emprego da linguagem como técnica e estratégia para se cumprirem determinados propósitos sociais, uma vez que a ênfase na exposição de boas bagagens produzidas com o PIBID logicamente implica na sua condição única de ação eficaz exercida no âmbito da formação inicial de professores, compreendo que o projeto, para os participantes em questão, incentiva e fortalece a docência na proporção em que oferece oportunidades adicionais de descobertas ao licenciando sobre o trabalho docente. Por extensão, consequentemente, a curiosidade e o investimento na ação fazem produzir neles variadas concepções sobre docência. A ampliação do programa a um maior número de pessoas equivaleria, portanto, à 
oportunidade de, diante de um contexto situado em que muitos ingressam para ter um ensino superior (OLIVEIRA, 2013), ou caem de paraquedas, experienciar outras possibilidades da atividade docente e, em decorrência disso, incentivar a futura profissão em contextos nos quais a figura docente se dissipa a cada dia.

Diante da impossibilidade de se ampliar o número de envolvidos ${ }^{3}$ e da estratégia de seleção de candidatos ao PIBID adotada pelo contexto de investigação, é preciso refletir sobre quem pode ser o bolsista ideal. Nem sempre escolher aqueles que possuem as melhores notas e produções seria uma postura pedagógica e politicamente corretas, haja vista a oportunidade de incluir no processo também o licenciando que possui dificuldades na construção de conhecimentos diversos, sobretudo nos didáticos e conteudísticos. Se o PIBID favorece ao licenciando a ativação de conhecimentos profissionais adicionais necessários, aqueles indivíduos que supostamente possuem mais dificuldades em termos de aprendizagem e de oportunidades também precisam ser democraticamente incluídos.

[13] Isso [indicar o perfil de estudante para participar do PIBID] é complexo. Porque se a gente parar para pensar, por exemplo, aquele aluno estudioso, ele tem notas boas, ele é o aluno ideal para entrar no PIBID. Eu, na verdade, penso o contrário. Eu acho que o PIBID pode ser um meio de intervir tanto nas escolas quanto dentro da faculdade, no sentido de que... É como eu vejo isso por mim [que entrei após a desistência de um bolsista]. A partir do momento em que ele [o aluno] entra no PIBID, ele tem outra visão [da docência]. Lógico que isso não é generalizado, não vai acontecer com todo mundo e tal. Mas eu acho que, se o aluno é bom, você percebe que ele já é bom ali no curso, no que está fazendo. Ótimo! Mas existem os alunos sobre os quais precisamos ter um olhar. Porque o PIBID pode ser um meio a partir do qual ele vai mudar esse pensamento. (Drica)

$\mathrm{Na}$ condição de um projeto em execução, que demanda tempo e engajamento, o processo de mudança, assim como o da construção da identidade profissional docente, é naturalmente processual. Como afirma Oliveira (2013), construirse professor demanda tempo e cuidado. No contexto de investigação de dupla licenciatura obrigatória - Letras: português e inglês -, por exemplo, o subprojeto auxiliou Anne a definir e a delimitar, na disciplina de língua portuguesa, a subárea com a qual deseja trabalhar futuramente.

[14] Uma [condição] que vai ficar para minha vida é que [o PIBID] me ajudou a definir a área em que eu quero aprofundar meus conhecimentos, que é produção textual, na área de língua portuguesa. Eu quero focar nisso! (Anne)

3. Em 02 de dezembro de 2015, a CAPES, por intermédio do Ofício 317/2015, suspendeu a inclusão de novos bolsistas no Sistema de Acompanhamento de Concessões e cortou a bolsa daqueles que já haviam recebido mais de 48 parcelas. 
A ação do PIBID, como podemos notar, não se apresenta integralmente verticalizada. O PIBID não é o agente que produziu esse desejo de ser professora em Anne. Do contrário, a participante tem plena noção da bagagem positiva que o programa lhe proporciona e, a partir dessa consciência crítica, do poder ativo de definição, de decisão e de acionamento, a professora em formação inicial automaticamente borra a condição de "entidade" do PIBID.

\section{5) Conscientização crítica e posicionamentos}

Manterem-se céticos quanto à realidade profissional e ao trabalho político e pedagógico docente no ambiente social constitui uma narrativa comum dos integrantes após passarem pela experiência do PIBID. Mesmo diante dos desafios observados e até enfrentados na carreira, nos relatos emergem a consciência crítica da realidade docente e oposicionamento diante daprofissão. Em suas narrativas, uma vez fortalecidos, geralmente se posicionam e dão contornos à sua identidade profissional docente à medida que se inscreve a certeza de se tornarem professores. Talvez guiados por outras motivações, uma característica marcadamente situada é o engajamento dos participantes à docência. Mesmo ao se depararem com a problemática escolar, enfrentam as dificuldades da profissão com convicção e otimismo.

[15] Em turmas que observamos, nós vimos, ali, turmas muito difíceis, mas em nenhum momento isso me fez querer desistir da profissão. Pelo contrário, motivou-me ainda mais com questões de pesquisa e me mostrou outros caminhos que o professor pode ter e percorrer na docência. [...] A profissão docente tem muitas dificuldades, percalços. Não tem o devido reconhecimento pelas pessoas, inclusive pelos próprios docentes atuantes. Porque, às vezes, estão desencantados com a profissão, por aspectos políticos, aspectos pedagógicos, leis externas e outras coisas, mas o PIBID, no caso, além de mostrar isso, nos mostra outros caminhos que você pode percorrer e mostra que o professor não pode ficar acomodado. Ele tem que pesquisar, ele tem que estar sempre atento às novas teorias, às novas tecnologias. Então, eu agora vejo a docência de um outro modo, né. Tem a dificuldade, mas é muito bom e eu gosto. (Flor do Campo)

Embora existam participantes que tenham interesse pela profissão docente previamente à chegada ao PIBID, tal qual Flor do Campo, o projeto proporciona aos integrantes amostras de outra realidade da prática pedagógica no ensino médio, conduzindo-os a uma consciência crítica das diferentes realidades e contextos de ensino existentes. Para a participante em destaque, por exemplo, houve uma ressignificação do imaginário social até então constituído por intermédio de sua prática e senso comum. A autorreflexão que apresenta a seguir também está a serviço daqueles que vão desde a graduação ao campo da ação munidos da crítica, da teoria e da reflexão sobre sua própria atuação e sobre os caminhos da docência. Afinal, quando o futuro 
professor se abre ao fazer docente, é possível avaliar e refletir sobre as experiências (re)construídas e, ao mesmo tempo, conhecer e agregar novas possibilidades com as quais se depara. Dinamicamente, é a teoria e a prática, configuradas sob um espectro de leitura fundante, que tornam o professor capaz de fundamentar-se e de explicar-se, bem como de consubstanciar a sua identidade profissional.

[16] Tinha certeza de que eu queria ser professora e já comecei a dar aula, né. Mas desenvolvendo o PIBID percebi outra realidade do ensino médio que eu não conhecia como professora. (Flor do Campo)

Obviamente esse pensamento dá margem ao pibidiano para compreender que, mais do que se configurar como um processo permeado de reflexão, o fazer docente é flexível, situado, contextualizado; portanto, não possui receitas quanto ao modo de se fazer. Mais ainda: o fazer docente é primordialmente passível de agência e, nesse caso, como destacamos, de engajamento.

Aos participantes, uma característica registrada corresponde à consciência crítica acerca dos papeis do professor e do trabalho com a disciplina de linguagem.

[17] O adjetivo seria mágica [o que eu acho da docência]. Porque você forma e transforma alunos, você está ali não só para ensinar a disciplina, não só para ensinar a gramática, ou literatura, o que seja. Os alunos saem dali também te vendo um professor, um exemplo de pessoa, de cidadania, de honestidade. Então, você também forma cidadãos, nós formamos outras profissões, né. [...] Um professor, a princípio, deve ser pesquisador. Então, ele deve pesquisar a sua sala. Cada sala vai ter um contexto diferente, os alunos vão pedir coisas diferentes. Deve ter também um bom domínio, não só da sua área, mas de outras áreas, para fazer interdisciplinaridade. Deve conhecer o que os alunos querem aprender também. Porque eu acho isso muito importante: [aprender] não só o que o Estado, o currículo pede, mas o que os alunos precisam aprender também de verdade. [...] Eu aprendi que o professor está muito além da disciplina de língua portuguesa. Então, ele vai ter outros desafios na sala, e você não pode fechar os olhos para eles, né. Você vai se deparar com o bullying, com o preconceito racial... Então, acho que mudou isso muito em mim. Porque eu, quando via a profissão docente, eu pensava: o professor é o que chega à sala e que vai ensinar gramática, e hoje eu já vejo diferente: eu sou professor, vou ensinar alguma coisa da disciplina, mas também vou me atentar ao que os alunos estão vivendo. (Carlos)

[18] [Um bom professor de línguas deve ter] Reflexão sobre a prática dele, sobre o que ele fala e que reflete diretamente nos alunos, se tem consciência também da responsabilidade que ele assume em sala de aula, principalmente de línguas. Porque trabalhar com a língua é trabalhar com a vida mesmo, com a dinâmica da sociedade. (Gonçalves)

[19] O professor é o profissional que deveria ser mais respeitado. Lógico que cada profissional tem a sua contribuição na sociedade, mas o professor é o formador de opinião, né? Então, levando-se em consideração que a escola é o lugar onde nós podemos formar pessoas críticas, capazes de mudarem a realidade na qual nós estamos inseridos, e que precisa ser mudada, cabe ao professor não só de Letras, português, inglês, mas outros professores também. Essa profissão é muito importante e às vezes eu penso que o governo sabe que essa profissão é importante. Principalmente por isso, ele não investe. (Drica) 
Entre os papeis docentes destacados pelos participantes estão os de a) pesquisador da sala de aula e da própria prática e b) pesquisador da própria disciplina. Quanto ao primeiro papel, é circunscrita a perspectiva de que o professor deve estudar e examinar constantemente sua ação e a de seus alunos, na tentativa de acionar práticas mais autênticas, contextualizadas e condizentes com a realidade dos discentes. No estudo de Cordeiro et al. (2015), o PIBID demonstrou-se essencial à formação docente à medida que escola básica e universidade se envolveram, e ensino e pesquisa não ficaram estanques.

Sobre o segundo papel recai a consciência crítica acerca da disciplina de língua/linguagem ministrada pelo professor de língua portuguesa. Contextualizando o itinerário, se o professor se aprofunda nos conhecimentos linguísticos dessa disciplina, automaticamente a sua atuação em sala de aula extrapola a lógica de conhecimento metalinguístico e resvala em outras possibilidades, tais como o acionamento de práticas que vão além da fragmentação disciplinar. O resultado dessa ativação incorre na consciência crítica docente de que língua/linguagem precisa(m) ocupar a característica interdisciplinar no âmbito pedagógico, porque certamente esse profissional compreende o que sejam língua/linguagem e o modo de se ensinar tais conceitos a partir dos conteúdos distribuídos de maneira encapsulada. Ambos os papeis, a meu ver, possibilitam ao futuro professor da disciplina o empoderamento para romper com paradigmas educacionais e linguísticos ainda hoje estacionados.

Os estudos de Oliveira et al. (2015) e de Guedes et al. (2015) afirmam que o PIBID da área de linguagem avança qualitativamente quando a língua é tratada, respectivamente, sob uma perspectiva social e interdisciplinar. Se, a exemplo do que ocorreu em Andrade et al. (2015) e em nossa proposta, o PIBID suplementa o trabalho com a língua/linguagem com sólidas leituras e discussões fundamentais à identidade docente, o projeto totalizante se confirma na coletividade, na coparticipação, na integração com o estágio supervisionado docente obrigatório. Logo, o PIBID se torna uma ação institucional complementar à formação inicial, projetada nas dimensões de fortalecimento da profissão docente na esfera social e de fortalecimento das licenciaturas e de professores.

As cinco bagagens apresentadas servem para refletirmos sobre a valiosa contribuição do PIBID para a construção e/ou a consolidação da identidade profissional docente em licenciandos de Letras no contexto investigado.

[20] Porque se fosse por muitos parentes e ex-professores eu não teria feito [licenciatura]. $\mathrm{E}$ até hoje eles mantêm o discurso [de que eu não deveria ter feito licenciatura]. Então, o que fica ao participar do PIBID é a certeza de que eu fiz a escolha [profissional] certa. (Flor do Campo) 
Acreditamos, pois, na força potencial complementar que o PIBID de Letras no contexto de investigação possui quanto à tarefa processual e auxiliar de fortalecer a escolba profissional daqueles que ainda frequentam uma licenciatura e ainda não se convenceram da profissão docente. Ouso dizer que o projeto propulsiona a legitimação das licenciaturas em geral em detrimento do baixo status da profissão docente e dos estigmas que tais cursos enfrentam ainda hoje e que se vislumbram em diversas narrativas docentes apresentadas aqui e em outros estudos (OLIVEIRA, 2013).

[21] Quando eu entrei na faculdade, eu tinha outros propósitos. Na verdade, eu nem sabia o que eu realmente queria, mas não era Letras. Meu pai não me deixou ir embora [da cidade em que moro e estudo], eu tinha acabado de fazer 17 anos. Então, acabou que eu fiquei aqui e pensei: "eu não posso ficar parada, eu vou cursar Letras então". Por que eu sempre me identifiquei com língua portuguesa e língua inglesa, sempre gostei. Então eu entrei no curso de Letras. No primeiro ano, levei ainda na expectativa de que no outro ano eu iria embora. Inclusive, se hoje for olhar a minha média lá no histórico acadêmico, minha media não é boa, justamente porque no primeiro e no segundo ano, eu não entrei de cara no curso. Quando então eu comecei o terceiro ano, que eu entrei para o PIBID, e os Estágios também, lógico que influenciam, eu comecei a ter outra visão, outro olhar. Lembrei de uma coisa que o Arroyo falou na palestra: "Que a gente não sente que vai ser professor, que é um dom, e tal. Não, você entra como você fosse entrar para a política, para politizar. [...] O PIBID foi, como diz, assim, portas e janelas que me fizeram ver, ter um horizonte, uma outra ideia do que era licenciar, no sentido de que eu me identifiquei. [...] Antes eu não tinha essa visão, hoje eu tenho. Acho que ser docente não é só ser "docente", mas ser "a docente". (Drica)

Diante de tantas narrativas apontando para os benefícios à construção da identidade docente, o PIBID ainda se prestou ao auxílio gradual e individual, na medida em que proporcionou a Gonçalves, por exemplo, a oportunidade de diminuir sua timidez e inibição, além do sentimento de incapacidade de ser professora.

[22] Eu tinha uma certa dúvida, acho que, na verdade, não era dúvida, mas um certo medo. Eu considero uma responsabilidade muito grande a de ensinar as pessoas. Então, acho que eu tinha medo de não ser capaz de ser professora, de ensinar as pessoas. Meu medo maior era esse. Então, por isso, vinha essa dúvida. Eu me considerava às vezes incapaz de chegar à frente de uma sala de aula, de ter toda aquela interação. Eu também tinha dificuldade de falar na frente de muitas pessoas. Então, era mais que uma barreira minha. Mas o PIBID me ajudou muito nesse ponto. (Gonçalves)

\section{CONSIDERAÇÕES FINAIS}

Ninguém viaja ao desconhecido sem levar consigo uma bagagem. Como viajantes que ingressaram na licenciatura, nem sempre é possível saber qual a bagagem que os professores em formação inicial trouxeram consigo, tampouco o que eles deixaram ou o que eles levarão a partir de sua estada na graduação. Porque 
são muitas as bagagens da licenciatura: atividades de formação diversas, estágio, PIBID etc.

Hoje escolhemos o PIBID. No entanto, sabemos que a saga em si fez profunda diferença no modo como os participantes desse projeto hoje se constroem na futura carreira. Como percebemos ao longo deste artigo, são dinâmicos e complexos os fatores que influenciam a construção positiva da identidade docente nos integrantes do PIBID. No entanto, cabe-nos criticamente alertar para o fato de que o diferencial na formação docente é a integração com outros projetos e atividades de profissionalização, as quais denotam e dão corpo à qualidade de trabalho formador ao longo da licenciatura.

O PIBID é um entre os muitos projetos que têm favorecido a construção da docência nos licenciandos. Todavia, estamos conscientes do teor qualitativo que cada ação de investimento deve ter e de sua dimensão conjunta em termos de formação inicial de professores. Por isso, deve ser um projeto articulado a outras propostas da formação profissional nas licenciaturas. É a partir do trabalho reflexivo e de ação na formação inicial, incluindo as bagagens trazidas pelo licenciando em confronto com as possibilitadas ao longo do curso, que esse indivíduo definirá, de forma consciente e crítica, a bagagem que ficará consigo ou a que será despachada para um outro destino.

\section{REFERÊNCIAS BIBLIOGRÁFICAS}

ANDRADE, A. A.; et al. (2015). O jornal escolar e a formação crítica do aluno do ensino médio: desvelando possibilidades através de gêneros textuais. Revista Ao Pé da Letra, v. 17.1, pp. 151-164.

AUDI, L. C. C. (2013). PIBID de língua inglesa na UNEB Câmpus X. Algumas contribuições na formação docente. In: Mateus, E.; El Kadri, M. S.; Silva, K. A. Experiências de formação de professores de linguas e o PIBID: contornos, cores e matizes. São Paulo: Pontes, pp. 79104.

BERGAMASCHI, M. A.; ALMEIDA, D. B. (2013). Memoriais escolares e processos de iniciação à docência. Educação em Revista, v. 29, n. 2, pp. 15-41.

BRASIL. (2006). Orientações Curriculares para o Ensino Médio: língua portuguesa. Brasília: MEC.

CORDEIRO, A. A.; et al. (2015). Ensino de língua portuguesa: o projeto de letramento "Música na ponta da língua". Revista Ao Pé da Letra, v. 17.1, pp. 59-76. 
DUBAR, C. (1997). A socialização: construção das identidades sociais e profissionais. Porto: Porto Editora.

EL KADRI, M. S. (2013). Retratos do movimento universidade-escola no interior do PIBID como prática social. In: Mateus, E.; El Kadri, M. S.; Silva, K. A. Experiências de formação de professores de línguas e o PIBID: contornos, cores e matizes. São Paulo: Pontes, pp. 105-129.

FAIRCLOUGH, N. (2010). Critical Discourse Analysis: the critical study of language. Harlow: Pearson Education Limited, 2010.

FETZNER, A. R.; SOUZA, M. E. V. (2012). Concepções de conhecimento escolar: potencialidades do Programa Institucional de Bolsa de Iniciação à Docência. Educação e Pesquisa, v. 38, n. 3, pp. 683-694.

GOIÁS. (2013). Secretaria de Estado da Educação. Currículo Referência da Rede Estadual de Educação de Goiás. Disponível em: <http: http://portal.seduc.go.gov.br/Documentos\%20 Importantes/Diversos/CurriculoReferencia.pdf $>$ Acesso em: 29 fev. 2016.

GOMES, B. D. S.; et al. (2015). O projeto PIBID e a formação docente: a construção identitária do professor de língua inglesa no alto sertão da Paraíba. Revista Ao Pé da Letra, v. 17.1, pp. 77-88.

GUEDES, A. R. M.; et al. (2015). O PIBID na elaboração e realização de atividades estratégias: bullying e aula de língua portuguesa. Revista Ao Pé da Letra, v. 17.2, pp. 31-46.

JORDÃO, C. M.; et al. (Org.). (2013). O PIBID-UFPR nas aulas de inglês: divisor de águas e formador de marés. Campinas, SP: Pontes Editores.

LIMA, A. C. A.; et al. (2015). Enunciados de sugestões didáticas: a escrita docente no PIBID Letras Português da UFPE. Revista Ao Pé da Letra, v. 17.1, pp. 41-58.

MAFRA, G. M.; CORRÊA, S. A. (2015). O PIBID como propiciador de capacidades docentes. Revista Ao Pé da Letra, v. 17.1, pp. 89-106.

MARCELO, C. (2009). Identidade docente: constantes e desafios. Formação docente: revista brasileira de pesquisa sobre formação de professores, vol. 1, n. 1, pp. 109-131.

MATEUS, E. (2011). Ética como prática social de cuidado com o outro. Implicações para o trabalho colaborativo. In: Magalhães, M. C. C.; Fidalgi, S. (Org.). Questões de método e de linguagem na formação docente. São Paulo: Pontes, pp. 187-209. 
MATEUS, E.; EL-KADRI, M.S.; SILVA, K.A. (Org.). (2013). Experiências de formação de professores de lingua e o PIBID: contornos, cores e matizes. Campinas, SP: Pontes Editores.

MATEUS, E. F.; OLIVEIRA, V.; SODRÉ, C. C. (2015). "O PIBID me salvou": a tecnologização de discursos e suas implicações nas práticas de formação de professores/as. Revista X, v. 1, pp. 32-51.

MOITA LOPES, L. P. (2002). Identidades fragmentadas: a construção discursiva de raça, gênero e sexualidade em sala de aula. Campinas, SP: Mercado das Letras.

NEITZEL, A. A.; PAREJA, C. J. M.; HOCHMANN, S. (2013). Práticas de leitura no ensino médio: o PIBID de Letras. Revista Brasileira de Estudos Pedagógicos, v. 94, n. 238, pp. $770-794$.

NÓVOA, A. (1992). Para uma análise das instituições escolares. In: Nóvoa, A. (Org.). As organizações escolares em análise. Lisboa: Publicações Dom Quixote, pp.13-43.

OLIVEIRA, A. A.; et al. (2015). Reflexões sobre o papel do bolsista de iniciação à docência do PIBID para o ensino de língua portuguesa na escola. Revista Ao Pé da Letra, v. 17.2, pp. 87-98.

OLIVEIRA, H. F. Esculpindo a profissão professor: experiências, emoções e cognições na construção das identidades docentes de licenciandos em Letras. 302f. 2013. Tese (Doutorado em Letras e Linguística) - Universidade Federal de Goiás, Goiânia, 2013.

PASSONI, T. P.; et al. (2013). Subprojeto PIBID de língua inglesa da UNEB/Câmpus X. Expecativas e possibilidades na formação de professores. In: Mateus, E.; El Kadri, M. S.; Silva, K. A. Experiências de formação de professores de línguas e o PIBID: contornos, cores e matizes. São Paulo: Pontes, pp. 131-154.

PENNYCOOK, A. (2001). Critical Applied Linguistics: a critical introduction. Mahwah, NJ: Lawrence Erbaum Associates.

PEREIRA, M. A. L.; ALMEIDA, P. C. A.; AZZI, R. G. (2002). A dimensão teóricoprática da Psicologia Educacional na formação de professores. A metodologia da problematização como desencadeadora da articulação entre teoria e prática. In: Azzi, R. G.; Sadalla, A. M. F. A. (Org.). Psicologia e formação docente: desafios e conversas. São Paulo: Casa do Psicólogo, pp. 181-206.

PICONI, L. B.; MATEUS, E. F. (2011). Ressignificações de identidades de professores. Uma análise do encontro com o outro. In: Reis, S.; Van Veen, K.; Gimenez, T. (Org.). Identidades de professores de línguas. Londrina: EDUEL, pp. 271-294. 
PIMENTA, S. G. (2012) Formação de professores. Identidade e saberes da docência. In: PIMENTA, S. G. (Org). Saberes pedagógicos e atividade docente. São Paulo, Cortez, 2012. pp. 15-38.

ROJO, R. H. R. (2013). Gêneros discursivos do círculo de Bakhtin e multiletramentos. In: Rojo, R. H. R. (Org.). Escola conectada: os multiletramentos e as TICs. São Paulo: Parábola, pp. 13-36.

RORRATO, D. C. C. P. (2014). O ensino colaborativo e a prática do PIBID. Revista Intercâmbio, v. XXIX, pp. 169-185.

ROZENFELD, C. C. F.; SALOMÃO, A. C. B. (2014). O trabalho de licenciandos de alemão e inglês no PIBID: a construção da prática docente a partir das crenças do ensino médio sobre língua e cultura estrangeira. Horizontes de Linguística Aplicada, v. 13, n. 1, pp. 159- 179 .

SILVA, T. T. (2009). A produção social da identidade e da diferença. In: Silva, T. T.; Hall, S.; Woodward, K. (Org.). Identidade e diferença: a perspectiva dos estudos culturais. 9 ed. São Paulo: Vozes, pp. 73-102.

SILVA, K. A.; GOMES, D. M. (2013). A (trans)formação de formadores e de professores de línguas no âmbito do PIBID (Letras) na UnB: perspectivas e desafios. In: Mateus, E.; El Kadri, M. S.; Silva, K. A. Experiências de formação de professores de linguas e o PIBID: contornos, cores e matizes. São Paulo: Pontes, pp. 49-78.

SMYTH, J. (1991). Critical pedagogy of supervision. In: Teacher as collaborative learners: challenging dominant forms of supervision. Buckingham: Open University Press, pp. 119-137.

STREET, B. (2014). Letramentos sociais: abordagens críticas do letramento no desenvolvimento, na etnografia e na educação. Tradução: Marcos Bagno. São Paulo: Parábola.

TEIXEIRA, I. S.; VASCONCELOS, J. S. (2015). Gêneros textuais e interdisciplinaridade: uma abordagem pertinente para o ensino de LP. Revista Ao Pé da Letra, v. 17.2, pp. $61-74$.

VIEIRA-ABRAHÃO, M. H. (2012). A formação do professor de línguas de uma perspectiva sociocultural. Signum, n. 15/2, pp. 457-480.

VYGOTSKY, L. S. (1998). A formação social da mente: o desenvolvimento dos processos psicológicos superiores. São Paulo: Martins Fontes.

Recebido: $14 / 12 / 2016$

Aceito: 16/11/2017 